\title{
To post or not to post?: perceptions of the use of a closed Facebook group as a networked public space
}

\author{
NEIL BALLANTYNE \\ The Open Polytechnic of New Zealand, Wellington, New Zealand. \\ SIMON LOWE \\ The University of Waikato, Hamilton, New Zealand. \\ LIZ BEDDOE \\ The University of Auckland, Auckland, New Zealand.
}

The expansion of social media is associated with rapid growth in digital spaces for civic engagement and deliberative democratic discussion. Yet while these networked public spaces offer many possibilities for engagement and interaction, the technology also shapes social dynamics, raising questions about managing professional relationships and boundaries online. The development of a closed Facebook for social workers in New Zealand provided an opportunity to explore their perceptions on the use of a shared social media space for information sharing, professional deliberation and debate about public issues: our findings highlight perceived benefits and pitfalls.

KEYWORDS: social media, social network sites, networked publics, Facebook, online incivility

\section{INTRODUCTION}

The rise of social media and the growth of social networking sites has created a proliferation of virtual spaces where people gather to chat, share content and associate with family, friends and people who share their interests. Some commentators argue that these online spaces are leading to new forms of civil society where citizens can engage in deliberative, democratic discussions within shared communities of practice (Varnelis \& Friedberg, 2008; boyd, 2010; Levine, 2000). In addition, many studies have traced the role of Facebook, Twitter and blogs in enabling people to debate and mobilise to take action on shared issues of concern across 
the world (Castells, 2015; Gerbaudo, 2012; Joyce, 2010, Tierney, 2013). Yet, whilst the affordances of networked public space offer many possibilities for engagement and interaction, the technology also shapes social dynamics: altering the distinction between the public and private and introducing unfamiliar communicative challenges such as blurred boundaries, collapsed contexts, and invisible audiences (boyd, 2010; Baym \& boyd, 2012).

The focus of this article is a study of a professional Facebook group called Social Work in Aotearoa New Zealand (SWANZ): this is a closed group which had 850 members at the time of the study. It was established and administered by a single individual social worker who created the group in October 2014 with the stated purpose of being "a safe place for social workers in Aotearoa New Zealand to meet and discuss issues relevant to our practice". It was envisaged as a closed community of practice for social workers, and the administrator vetted all people requesting membership to ensure that they were indeed social workers. Social media has been subject to increasing attention over recent years within the social work literature, with topics spanning concerns about privacy, confidentiality and professional conduct (Kimball \& Kim, 2013; Reamer, 2013; Sage \& Sage, 2015). In addition, more positive readings have considered the potential social media carry for learning and professional development (Stanfield \& Beddoe, 2016). Social work has been called upon to consider the impact and potential of social media because of its significant influence on local societies, its potential for practice and its prospective power as a tool for advocacy on social justice issues (Stanfield \& Beddoe, 2016).

Four members of the research team were members of SWANZ, shared an interest in social media within the social work profession, and have been active participants in discussion and debate within the group. Following an announcement by the New Zealand government of plans to reform child protection services and alter the structure and funding of social services, SWANZ became a place where group members shared information about proposed policy changes and discussed and debated these and other issues. As participants we observed the ebb and flow of discussion and noticed the growth of interest in the group, indicated by a rapid rise in membership. We also observed that, as in other online communities, some members were very active in making contributions and comments to the online discussion, but the vast majority were relatively passive participants (they may be logging in and reading content posted to the group but made no little or no active contributions to discussion or debate). The study aimed to explore with participants factors associated with active 
engagement in this networked public space, and factors associated with reluctance to participate. Our specific research questions were:

1. What do participants value about their membership of the SWANZ Facebook group?

2. What problems or issues are associated with membership?

3. What factors are associated with active engagement and with reluctance to participate in the SWANZ community?

We hoped to to utilise the findings to inform the development of professional use of social media by the social work profession and to better understand how social workers might use online networks to debate public issues.

\section{LITERATURE REVIEW}

The literature review is focused on two topics of significance to this study: firstly an exploration of how social networking sites operate as networked publics, and secondly consideration of the research on civic engagement and online incivility. The latter topic is explored because the idea of democratic deliberation is highly relevant to purposes of the SWANZ Facebook group, as is the way in which the affordances of social media can have unanticipated effects on interpersonal communication.

\section{Social Networking Sites as networked publics}

In the second quarter of 2016 the world's largest social network, Facebook, was reported to attract 1.71 billion monthly active users (Statista, 2016). The global reach and pervasive use of social media have transformed how people create, collaborate and maintain social relationships. Social networking sites (SNS) provide internet based services that allow people to construct a digital profile and reach across conventional barriers of time and space to connect with others anywhere in the world. However, the connections people choose to establish are often carefully focussed on aspects of their personal or professional identity (boyd, 2010; Baym and boyd, 2012). boyd (2010) terms these new digital spaces networked publics:

Networked publics are publics that are restructured by networked technologies. As such they are simultaneously (1) the space constructed through networked technologies and (2) the imagined collective that emerges as a result of the intersection of people, technology and practice. (p. 39) 
boyd's (2010) reference to an imagined collective resonates with Anderson's (2006) notion of a public as an imagined community, a phrase coined to describe the idea of national identity and the sense that people have of being part of a national community even though they could not possibly engage in face-to-face communication with all of its members. Another important facet of the concept of publics is its plurality: there is not one common public sphere but many publics some of which may be open and inclusive, other more exclusionary and some that might be termed counterpublics "formed by their conflict with the norms and contexts of their cultural environment" (Warner, 2002, p. 63). Networked publics share a similar function to real world public spaces where people congregate: for example, cafés, places of employment, clubs, and the home (Varnelis \& Friedberg, 2008). However, as boyd (2010) argues, networked publics "extend and complicate publics" (p.41). The informational architecture of a social network site (the capacity it provides to create a profile, connect with friends, join a group, post, comment, share, like or block other users) offers its users particular constraints and affordances on their actions that alter the usual boundaries of social interaction (boyd, 2010; Baym \& Boyd, 2012).

The architecture and affordances of SNS also offer users fresh opportunities, new challenges, and a digital space for the performance of self and the management of impressions (Goffman, 1959; Sleeper et al, 2013; Mor et al, 2015). Social media users respond to these opportunities and challenges in different ways. As Baym and boyd (2012) suggest, "Some develop a sensibility through experience; others find themselves struggling to make sense of and manage their participation in networked publics; some misunderstand the consequences of their actions and make mistakes without realizing it" (p. 328). Mor et al. (2015), for example, studied the complex strategies adopted by Israeli youth to manage political expression on Facebook in a highly charged and divisive political context, and Sleeper et al. (2013) explored how Facebook users self-censored around half of their potential content in order to manage the presentation of self and avoid unwanted arguments or discussions. For a minority of users social media offer a context to engage in behaviours, perceived by others, to be deliberately aggressive, hostile or rude.

Civic engagement and online incivility 
The motivations for people to use SNS include personal, professional and political reasons, information seeking and civic engagement (De Zuniga \& Valenzuela, 2011; Graham, Jackson $\&$ Wright, 2014). One of the bi-products of the information-sharing activities of individuals is that the digital space can inadvertently, or purposefully, become a political space. In fact, some proponents argue that the internet has a critical role in increasing political participation and deliberative democratic discussion (Papacharissi, 2004), thus halting, or reversing, recent declines in the public sphere and civic engagement (Levine, 2000; Putnam, 1995, 2000). Other commentators counter that the digital domain ushers in its own problems including online incivility (Papacharissi, 2004; Santana, 2014), hostile verbal behaviour or flaming (Hutchens et al., 2015), and the cyberbalkanisation of the internet or its fragmentation into a multitude of 'like-minded' groups (Dahlberg, 2007; Putnam, 2000).

Discussion is the primary activity of social networking and is also key to democratic political engagement, as it creates opportunities for social learning and attitude formation (Johnson, Zhang, Bichard, \& Seltzer, 2011). Indeed, evidence suggests that individuals who engage in discussion with those who hold opposing views are more likely to be tolerant of the opinions of others, aware of different perspectives, and hold complex political views (Mutz, 2002; Evelend and Hively, 2009). Within civil society there is an expectation that individuals have the right to their own beliefs and opinions. Offensive comments that deny respect for social groups or individuals impede the democratic ideal that robust but respectful discussion should characterise political activity (Papacharissi, 2004; Santana, 2014). Online incivility can be conceptualised as "attacks that go beyond differences in opinion and that devolve into namecalling, contempt and derision" (Santana, 2014, p21). As Hutchens et al. (2015) put it, "The conversation moves from: 'I disagree with your position on health care' to 'I disagree with your socialistic, un-American position on health care.' " (p. 1203).

Issues of public concern often cultivate healthy debate and heated discussion. However, conversations permeated with incivility can overshadow meaningful conversations and lead to disillusionment, disengagement and psychological stress (Anderson et al., 2014). As Santana (2104) argues "Discursive incivility induces defensive reactions instead of deliberative ones and often leads to a collapse in deliberative dialogue.” (p.21) Online anonymity (where users can choose screen names or avatars that conceal their true identity) is especially associated with incivility; a problem that has been studied in relation to online newspaper commenting forums (Santana, 2014) and that Rowe (2014) has shown can be 
managed, although not eliminated, by requiring users to log on using a Facebook account that confirms their identity.

\section{METHOD}

Many studies of online interaction in social media spaces such as Facebook use the actual online interactions between participants as the primary data source, perhaps conducting a social network analysis of their relationships. This approach yields excellent empirical data allowing researchers to observe and trace relationships over time and analyse the actual content of communications. When these communications occur in a space that is accessible on the open internet some researchers consider this to be publically accessible data with no need for informed consent. However, as Markham and Buchanan (2012) point out, "The ethical parameters for collecting information in online public spaces are ambiguous and contested" (p. 13). In a closed Facebook group like SWANZ it is highly likely that participants expect their communications to be kept private to the community, even although they might be aware of the potential for breaches of that expectation. In that context the informed consent of participants would be required before making ethical use of conversational data. However, the research team considered that seeking the informed consent of 850 individuals for access to communications that had taken place over a year prior to making the request, was not a feasible approach. We therefore decided to invite members of the group to take part in an online survey and to interview a sample of survey participants. This article focuses on the findings from the online survey, and the interview data will be reported in a subsequent article. The project was approved by the ethics committees of two universities and one polytechnic: the University of Auckland, the University of Waikato and the Open Polytechnic.

We established the approval of the SWANZ administrator and posted an invitation to participate in the survey in the SWANZ Facebook group with a link to the survey. The survey landing page linked to a participant information sheet. Agreeing to participate in the survey was taken as consent to participate. The questionnaire was created using the online survey software Qualtrics and consisted, mostly, of quantitative questions designed to collect demographic data, data about participants' use of Facebook, extent of political activism, levels of activity within SWANZ, and questions about participants' opinions towards the use of SWANZ. There were two open-ended qualitative questions one of which asked participants to elaborate on their responses to a question about whether they had ever 
considered leaving SWANZ, and the other was a final question inviting participants to add "any other comments you wish on your involvement with the SWANZ Facebook group". We noted above that most of the research team were members of the SWANZ Facebook prior to the research, albeit with varying degrees of participation. Like the majority of SWANZ participants we used real names and our Facebook profiles made it evident who we were and where we worked. Included amongst the SWANZ participants were colleagues, students and former students. As such we could be classified as insider researchers (Dwyer \& Buckle, 2009) although with the distinction of being well informed about the topic as an intellectual endeavour. The latter point is important as our participation in the research was both as members of the community under study and scholars in the field.

\section{FINDINGS}

\section{Participants}

Fifty-three participants from the closed group of 850 responded to the survey $(6.23 \%$ of the population of interest). The majority of participants were aged between 35 and 54 (69\%) with $25 \%$ aged over 54 years of age and only $6 \%$ younger than 35 years. The majority of participants identified as female (75\%) and the remainder as male (25\%). In keeping with the approach to ethnicity identification used by Statistics New Zealand, participants could identify with more than one ethnicity (and so the percentages add to more than 100\%): the majority (79\%) identified as being of New Zealand European ethnicity, 12\% as Māori and $25 \%$ as other. In response to a question about their highest qualification $34 \%$ stated they had a bachelors or bachelors with honours qualification, $12 \%$ a postgraduate certificate or diploma, $38 \%$ a master's degree and $6 \%$ a doctorate. Only $10 \%$ reported having a sub-degree diploma qualification.

Twenty-six percent indicated that their primary place of work was in a non-governmental organisation (with $2 \%$ in indigenous, iwi social services), $22 \%$ worked in a government organisation (Child, Youth and Family, or District Health Board), 27\% in a tertiary education organisation, and $12 \%$ were students. Fourteen percent worked in other settings. On the whole the participants' demographic profile looks very similar to the demography of the social work workforce with the exception of place of work. Here it is clear that that the sample included a disproportionate number of people working within tertiary education institutions who are likely to be social work academics, which may explain their relatively 
high level of educational qualifications. In fact, academics and students made up over a third $(39 \%)$ of the sample.

\section{Use of Facebook}

The sample were active users of Facebook with $89 \%$ using it at least daily (and 71\% more than once each day). Six percent accessed Facebook four to six times each week, and 6\% two to three times each week. Most (78\%) had had a Facebook account for more than five years, $20 \%$ for more than two years and the remainder (2\%) for more than a year.

\section{Activism}

To measure levels of political activism the survey asked participants to report on their affiliations to political and other campaigning organisations and included a direct question on whether they considered themselves to be an activist. Over half of participants $(56 \%)$ were members of the Aotearoa New Zealand Association of Social Workers, almost a third (29\%) were members of a campaigning issue based organisation (e.g. Greenpeace, Amnesty International etc.), over a quarter were paid up members of a political party $(27 \%)$, and $60 \%$ were members of a trade union. Sixty-eight percent of participants agreed, or agreed strongly, that they would describe themselves as a social or political activist.

The survey also asked participants to position themselves on a ten-point political spectrum scale where one was "left wing" and ten was "right wing". The majority positioned themselves on the left of the scale with a mean score of $3.13(\mathrm{SD}=1.84)$.

\section{Responses to government}

Bearing in mind that the SWANZ Facebook group was launched just before several major government efforts to reform child protection and social services in New Zealand the survey asked participants two questions about their responses to government: one asked how often, in the last year, the actions of the government of New Zealand made them feel frustrated; the second asked how often the actions of government made them feel angry or outraged. On a five-point Likert scale where one was "never", and five was "all of the time", $81 \%$ percent stated that they felt frustrated at the actions of the NZ government either often or all of the time, and $67 \%$ felt angry or outraged either often or all of the time. 


\section{Levels of political activity and perceived political efficacy|}

All but two participants had been active in some sort of political activity in the last year, ranging from $91 \%$ who had signed a petition to $5 \%$ who had joined a political party. The high proportion of petition signers may be an effect of the growth of online petitions promulgated by organisations like ActionStation (ActionStation Aotearoa, 2016). However, our participants are not only digital activists but also engaged in face-to-face activity with $50 \%$ attending public demonstrations and $68 \%$ participating in public forums or debates. That many use their own initiative to take action is suggested by the $36 \%$ who have written to an MP and the $14 \%$ who have written to mainstream media.

\section{[INSERT TABLE 1]}

In order to assess participants' sense of political efficacy the survey asked them to rate the extent to which they believed their actions could influence the decisions made by the New Zealand government on a ten-point scale from $1=$ not at all, to $10=$ a great deal: the resulting mean was 5.02 suggesting that political efficacy was perceived to be mid-range, although the range of responses here was quite wide $(\mathrm{SD}=2.24)$.

\section{Levels of engagement with the SWANZ Facebook group}

The duration of participants' membership of the SWANZ Facebook group ranged from more than a year $(40 \%)$, to six to twelve months $(34 \%)$, to less than six months $(28 \%)$. Levels of engagement in the group varied from those who logged in at least daily (35\%), to at least 2 to 3 times a week (48\%), to at least once a month (16\%).

\section{What participants valued about SWANZ}

From a list of eight statements about aspects of the SWANZ membership that participants' valued most feeling connected to a wider community of practice was recognised by $80.25 \%$ of participants as valuable or very valuable. This was quite closely followed with the value participants placed on being able to post and share information on issues relevant to the social work community (77.08\% stating this was valuable or very valuable). If being part of the community and being able to contribute was valued, so too was obtaining access to 
information (75\% stating this was valuable or very valuable) and links to open access journal articles and other professional development materials (74.47\% stating this was valuable or very valuable).

\section{[INSERT TABLE 2]}

The item on our list of statements that was least valued was Feeling empowered, able to take a stand, and question and challenge the views of government with only $46.81 \%$ recognising this as valuable or very valuable.

\section{Negative aspects of SWANZ}

To explore the possible negative aspects of participation in SWANZ participants were asked to indicate the extent to which they agreed or disagreed with statements about the volume of posts to the group, the relevance of posts and whether policy and political discussion was felt to be polarising. Most participants appeared not to have an issue with these aspects of participation with only $10.42 \%$ agreeing, or agreeing strongly, that the volume of posts was overwhelming, $12.5 \%$ that policy and political discussion were polarising, and $12.5 \%$ that many posts were not relevant.

Asked if they have recommended the SWANZ Facebook group to others, $64.58 \%$ indicated that they had. However, when asked whether they had ever considered leaving the group over a third (37.5\%) indicated they had considered leaving. Thirteen participants $(27 \%)$ offered their reasons for considering leaving the group, and twelve of the statements made referred to the tone of the contributions made by some individuals who were described as "dominant", "bullying", "rude", "offensive" and "aggressive". For example, one stated that:

sometimes discussion on important issues goes beyond "challenge" and becomes more accusatory and attacking. While described as a 'safe' space to discuss openly, the way discussions go sometimes don't feel very open or safe at times. I get that people are passionate about causes, but the times when things have descended to personal attack it has made me wonder if it was a safe enough space to say anything at all. (Participant \#42) 
We cannot be certain but these statements may have been related to recent events within the group as one participant stated that "More recent polemic on posts...last six months or so, unhelpful, critical and disrespectful posts that don't honour our profession" (Participant \#13); and three participants refer to an individual who was recently removed from the group: "Because of the nasty comments made by some members which is polarising and unethical. Very pleased to see a member removed recently due to some of the comments he made" (Participant \#16). Whilst it is not clear that all of these participants are referring to the same people or issues, or would have the same point of view on these issues, two make mention of "difficult" discussions around racism and culture.

\section{Activity levels in SWANZ}

The next section of the survey explored the activities undertaken by participants in the SWANZ Facebook group asking how frequently they started a new post, commented on an existing post, liked a post, or shared a post with another group.

\section{[INSERT TABLE 3]}

The majority of participants (70.83\%) rarely or never started new posts in the SWANZ group although over half (57.44\%) sometimes or often commented on the posts of others.

\section{Reluctance to express policy or political views}

The survey asked whether participants had ever felt reluctant to express a point of view on policy or politics within the SWANZ group and over three quarters (77\%) agreed that they had. Asked to select from some statements of possible reasons for this reluctance, the reason selected by $70.59 \%$ of participants was I worry that I may be subject to critical comments by others in the group who do not share my views. That this perception may relate to recent events in the group is suggested by the response to the final question which asked participants to make any additional statements they wanted to about the SWANZ group.

\section{[INSERT TABLE 4]}

\section{Other comments}

The final question invited participants to add any other comments they wished on their involvement with the SWANZ Facebook group. Twenty five participants $(47.17 \%$ of the 
sample) added comments several of which were at some length giving a commentary of 1,405 words in total. A thematic analysis of these comments identified three main themes: the first, was on the value of the Facebook group as a professional network; the second, and most commented upon, was the issue of participants concerns with netiquette or online incivility, and the third was a specific comment about the groups ability to deliberate on matters of racism.

Several participants recognised the "potential value in the group as a networking tool" (Participant \#42) and as a "way to connect to the community of social work" (Participant \#39). Participant \#25 stated that "I believe social media such as the SWANZ group are a very important way to network and disseminate information in a very timely manner". However, the comments of each of these participants, and several others, suggest that the SWANZ Facebook group may not be achieving its networking, community building potential. The concern shared by most participants was in relation to what we might refer to as lapses in netiquette or online civility. For example:

It's more that I don't want to endorse a faceless discourse with people who clearly are not willing to have a reasoned discussion but simply wish to rage, lash out and be righteous. It seems like a lose-lose for all involved. I don't wish to put people off being part of a social work community! So at times I have felt reluctant or demotivated about posting issues or comments. (Participant \#5)

Another aspect that creates a barrier to contribute to threads on this page is that I often feel that the same people critique/pull apart views which they may not deem to be "acceptable". I can't be bothered with in-fighting, not enough time in the day to play that game! (Participant \#44)

Participants expressed concerns about "trolling, bullying and abusive behaviour" (Participant \#23) that robust deliberation sometimes turned into aggressive personal attacks, and that comments could be misconstrued and even hijacked:

I have seen a few 'hijackings' take place on the page that both frustrate and intimidate me. I am acutely aware of the social, political and cultural issues impacting on society and will always work to educate and address these ... In the meantime, there is 
also the 'day to day' practice issues which I would like to discuss but get too scared to bring up.(Participant \#22)

Several participants referred to the topic of racism as a source of difficulty for open discussion in the SWANZ Facebook group and the two quotations that follow articulate two perspectives on this matter:

There has been a recent discussion about racism and white supremacy which I have found difficult to express my true opinion due to concerns about being labelled racist. I have felt gagged by the narrative. (Participant \#3)

I don't worry about being subject to critical feedback or constructive feedback but I feel the group has foundered at times and been unable to tolerate critical discussion particularly around issues to do with racism resulting in personalisation, pathologization and reductionism. (Participant \#33)

\section{DISCUSSION}

This study was conducted to address four research questions: What do social work participants value about their membership of the SWANZ Facebook group? What problems or issues were associated with membership? What factors are associated with active engagement and with reluctance to participate in the SWANZ community? Our assumption is that answers to these questions might illuminate factors associated with the development of other professional social networking sites. However, we need to note from the outset the limitations on making generalisations from what is, in effect, a relatively small case study with a limited number of participants $(n=53)$ from a much larger online community $(n=$ 840). We also need to recognise, as noted above, the researchers' role as participants in the SWANZ community and therefore as insider researchers (we will return to these points when discussing study limitations below).

The demographic details of our participants revealed them to be preponderantly female, midadulthood, and with relatively high academic qualifications. Detailed statistics on the demography of the contemporary social work workforce in New Zealand are not available however, we do know that it is an older age demographic and is predominantly female. One 
feature of the sample that suggests it is not representative of the workforce, or the SWANZ Facebook group, it the high proportion of social work educators included.

It is quite clear that our participants valued many aspects of SWANZ Facebook group and that the three most highly rated aspects of their participation were feeling connected to a wider community of practice; being able to post and share information on issues relevant to the social work community; and quick and easy access to the latest news and information on matters relevant to social work practice. So, the feeling of being connected and the ability to contribute to the community are rated even higher than accessing information posted by others (helpful although this may be). Curiously, for a group of social workers who appear to be social and politically active, and who could reasonably be described as being dissatisfied with the recent actions of government, the statement that fewest respondents considered to be valuable was feeling empowered, able to take a stand, and question and challenge the views of government. This may connect to the general sense of political efficacy indicated above, or it may refer to the extent to which the SWANZ Facebook group is perceived as a potential vehicle for the mobilisation of political activity.

Considering negative factors associated with their use of the SWANZ group our participants were unconcerned with the volume of posts, with irrelevant posts or with discussion becoming polarised. In fact, the majority encouraged other social workers to become participants. And yet over a third of participants admitted they had actively considered leaving the group at some time. Featuring strongly amongst the reasons offered for leaving the group was what was described as the "domineering", "bullying", "rude", "offensive" and "aggressive" interactions with some group members. This theme is picked up again in relation to a question on reluctance to express a point of view on policy or politics where the standout statement (agreed by $70.59 \%$ of participants) is I worry that I may be subject to critical comments by others in the group who do not share my views.

Given that the majority of our sample include mature, educated social workers (many of whom are educators) who also identify as political and social activists, this seems an extraordinary finding. One of the issues confronting users who are members of a Facebook group is that, unlike their personal wall where they can select their friends, they have no choice over who the other members are; and, in a large group like SWANZ, they are highly unlikely to know all of the participants. Therefore, short of blocking a user altogether, as 
identified by Sleeper et al. (2013), self-censorship is the only way for users to manage the presentation of self and avoid unwanted arguments or discussions.

One of the curious aspects of the incidents referred to by our participants is that these acts of online incivility occurred in a closed community of social work practitioners where one might expect relative homogeneity and a shared value base. Indeed, as Suhay et al. (2015) highlight, online incivility in particular partisan communities tends to be directed at an outgroup which, in this case, might be expected to be the governmental actors responsible for making social policy reforms, controversial reforms that have been widely debated in public media. The fact that incivility, in this instance, appeared to be directed at people inside the group and was, according to some respondents, associated with discussions of race, culture and allegations of white supremacy suggests that the individual, or individuals involved, may have associated with a counterpublic and considered the members of SWANZ to be the outgroup. This, however, is speculation and, without access to data observing actual online behaviours, is impossible to confirm.

Two final points to note about possible lack of homogeneity in the membership of the SWANZ Facebook group is that, although the volunteer administrator stated that all members were checked to confirm that they were social workers, the definition of who is a social worker in Aotearoa New Zealand is contested. Although, the Social Workers Registration Board (SWRB) exists to register social workers in New Zealand, and the majority of governmental social workers are required to be registered, registration is not mandatory and the title of social worker is not protected. Therefore, anyone can identify themselves as a social worker without necessarily subscribing to the code of ethics of the professional body, or the code of conduct of the SWRB. Secondly, whilst responses to this survey were being collected (between January and February 2015) the code of conduct of the SWRB was revised and a new version, including, for the first time, explicit reference to the use of social media was published in March 2016.

In terms of the limitations on our study, the low number of participants, in comparison with the number of members of the SWANZ Facebook group, meant we could not conduct more sophisticated analyses of the quantitative data. Several factors may have impacted on participation. Firstly, we launched the survey during the Southern Hemisphere's summer holiday period. Secondly, the flurry of negative postings referred to by participants happened 
just before the survey was launched and may have had a negative impact on people logging in to the group. Thirdly, as noted earlier, we were insider researchers, and thus, by virtue of our participation in the Facebook group, may not have been perceived as neutral and this may have influenced participants' decisions to participate or not. Finally, as a self-report survey, the views expressed by participants may not accurately reflect their actual behaviours in the online community. In spite of these limitations, as a small case study of an online community of practice for social workers, we believe the study offers some valid insights into the dynamics of online interaction and the chilling effects on participation of online incivility.

\section{CONCLUSIONS}

Considered as an exploratory case study our findings highlight the potential benefits and pitfalls associated with the use of a networked public space for debating issues of concern to professional social workers. The creation of an online community of practice in which users can engage and share news, information and opinions was valued highly. However, in this case study, there were issues associated with examples of online incivility and a pervasive reluctance to express policy or political opinions because of concerns about critical comments by others. What is not clear is the extent to which concerns about critical feedback are just a normal, and sensible, part of interaction in networked public spaces; and the extent to which our respondents were reacting to a group climate and recent events in this particular Facebook group. It is also possible that sensitive issues, such as race and culture, pose particular dilemmas for democratic deliberation in the context of a postcolonial society where indigenous people are vastly over-represented in the care and justice systems.

Although there would be ethical barriers to be overcome, deeper insight into the communication patterns and styles in networked public spaces for professional social workers (and other professional groups) might be best obtained by adapting methods from the emerging scholarship associated with digital ethnography (Pink, et al, 2016).

\section{REFERENCES}

ActionStation Aotearoa. (2016). ActionStation: People powered change. Retrieved from http://www.actionstation.org.nz/ 
Anderson, A. A., Brossard, D., Scheufele, D. A., Xenos, M. A., \& Ladwig, P. (2014). The "nasty effect:" Online incivility and risk perceptions of emerging technologies. Journal of Computer-Mediated Communication, 19(3), 373-387.

Anderson, B. (2006). Imagined communities: Reflections on the origin and spread of nationalism. London, England: Verso.Baym, N. K., \& boyd, d. (2012). Socially mediated publicness: An introduction. Journal of Broadcasting \& Electronic Media, 56(3), 320-329. doi:10.1080/08838151.2012.705200

boyd, d. (2010). Social network sites as networked publics: Affordances, dynamics, and implications. In Z. Pappacharissi (Ed.), Networked self: Identity, community, and culture on social network sites (pp. 39-58). New York: Routledge.

Castells, M. (2015). Networks of outrage and hope: Social movements in the internet age (2nd ed.). Cambridge, England: Polity Press.

Dahlberg, L. (2007). Rethinking the fragmentation of the cyberpublic: from consensus to contestation. New Media \& Society, 9(5), 827-847. doi:10.1177/1461444807081228

de Zúñiga, H. G., \& Valenzuela, S. (2011). The mediating path to a stronger citizenship: Online and offline networks, weak ties, and civic engagement. Communication Research, 38(3), 397-421.

Dwyer, S. C., \& Buckle, J. L. (2009). The space between: On being an insider-outsider in qualitative research. International Journal of Qualitative Methods, 8(1), 54-63.

Gerbaudo, P. (2012). Tweets and the streets: Social media and contemporary activism. London, England: Pluto Press.

Goffman, E. (1959). The presentation of self in everyday life. New York: Doubleday.

Graham, T., Jackson, D., \& Wright, S. (2015). 'We need to get together and make ourselves heard': Everyday online spaces as incubators of political action. Information, Communication \& Society, 1-17. doi:10.1080/1369118x.2015.1094113 
Hutchens, M. J., Cicchirillo, V. J., \& Hmielowski, J. D. (2015). How could you think that?!?!: Understanding intentions to engage in political flaming. New Media \& Society, 1461444814522947-. doi:10.1177/1461444814522947

Johnson, T. J., Zhang, W., Bichard, S. L., \& Seltzer, T. (2011). United we stand? Online social network sites and civic engagement. In Papacharissi, Z., (ed). A networked self: Identity, community, and culture on social network sites. (pp.185-207). London: Routledge, 2010.

Joyce, M. (Ed.). (2010). Digital activism decoded: The new mechanics of change. New York: International Debate Education Association.

Kimball, E., \& Kim, J. (2013). Virtual boundaries: ethical considerations for use of social media in social work. Social Work, 58(2), 185-188.

Levine, P. (2000). The Internet and civil society. Report from the Institute for Philosophy and Public Policy, 20, 1-9. Retrieved from http://www.puaf.umd.edu/ippp

Markham, A., \& Buchanan, E. (2012). Ethical decision-making and internet research: Recommendations from the AoIR ethics working committee. Retrieved from http://www.aoir.org/documents/ethics-guide

Mor, Y., Kligler-Vilenchik, N., \& Maoz, I. (2015). Political expression on Facebook in a context of conflict: Dilemmas and coping strategies of Jewish-Israeli youth. Social Media + Society, 1(2), 1-10. doi:10.1177/2056305115606750

Mutz, D. C. (2005). Cross-cutting social networks: Testing democratic theory in practice. American Political Science Review, 96(1), 111-126.

Papacharissi, Z. (2004). Democracy online: Civility, politeness, and the democratic potential of online political discussion groups. New Media \& Society, 6(2), 259-283.

Pink, S., Horst, H., Postill, J., Hjorth, L., Lewis, T., \& Tacchi, J. (2016). Digital ethnography: Principles and practice. London, England: Sage. 
Putnam, R. D. (1995). Tuning in, tuning out: The strange disappearance of social capital in America. Political Science and Politics, 28(4), 664-683. Retrieved from http://www.uvm.edu/ dguber/POLS293/articles/putnam1.pdf

Putnam, R. D. (2000). Bowling alone: The collapse and revival of American community. New York: Simon \& Schuster.

Reamer, F. G. (2013). Social work in a digital age: Ethical and risk management challenges. Social Work, 58(2), 163-172. http://doi.org/10.1093/sw/swt003

Rowe, I. (2014). Civility 2.0: A comparative analysis of incivility in online political discussion. Information, Communication \& Society, 4462(July), 1-18. doi:10.1080/1369118X.2014.940365

Sage, M., \& Sage, T. (2015). Social media and e-professionalism in child welfare: Policy and practice. Journal of Public Child Welfare, 10(1), 79-95. DOI: $10.1080 / 15548732.2015 .1099589$

Santana, A. D. (2014). Virtuous or vitriolic: The effect of anonymity on civility in online newspaper reader comment boards. Journalism Practice, 8(1), 18-33. doi:10.1080/17512786.2013.813194

Sleeper, M., Balebako, R., Das, S., McConahy, A. L., Wiese, J., \& Cranor, L. F. (2013). The post that wasn't: Exploring self-censorship on Facebook. In Proceedings of the 2013 conference on Computer Supported Cooperative Work. San Antonio, Texas: ACM. doi:10.1145/2441776.2441865

Suhay, E., Blackwell, A., Roche, C., \& Bruggeman, L. (2015). Forging bonds and burning bridges: Polarization and incivility in blog discussions about occupy Wall Street. American Politics Research, 43(4), 643-679. doi:10.1177/1532673X14553834

Stanfield, D., \& Beddoe, L. (2016). Social work and social media in Aotearoa New Zealand: Educating social workers across shifting boundaries of social work identity. Social Work Education, 35(3), 284-296. doi:10.1080/02615479.2016.1154663 
Statista. (2016). Number of monthly active Facebook users worldwide as of 2nd quarter 2016 (in millions). Retrieved from http://www.statista.com/statistics/264810/number-ofmonthly-active-facebook-users-worldwide/Tierney, T. F. (2013). Disentangling public space: Social media and internet activism. Thresholds, 82-89.

Varnelis, K., \& Friedberg, A. (2008). Place: The networking of public space. In K. Varnelis (Ed.), Networked publics (pp. 15-42). Massachusetts: MIT Press.

Warner, M. (2002). Publics and counterpublics. New York, NY: Zone Books. 
TABLE 1 Participants' political activity in the last year

\begin{tabular}{lll}
\hline Political activity & $\mathrm{N}$ & Percentage \\
\hline Written to or met with an MP to express a point of view & 16 & $36 \%$ \\
Attended a public demonstration & 22 & $50 \%$ \\
Joined a political party & 2 & $5 \%$ \\
Joined a campaigning issue based organisation & 21 & $48 \%$ \\
Attended a public forum or debate & 30 & $68 \%$ \\
Signed a petition & 40 & $91 \%$ \\
Sent a letter to the mainstream media & 6 & $14 \%$ \\
Other & 7 & $16 \%$
\end{tabular}


TABLE 2 What participant's valued about SWANZ

Statements
1. Quick and easy access to the latest
news and information on matters
relevant to social work practice $(\mathrm{N}=$
$48)$

2. Useful information on open access

\begin{tabular}{lllll}
$\begin{array}{l}\text { Not } \\
\text { valuable }\end{array}$ & $\begin{array}{l}\text { Limited } \\
\text { value }\end{array}$ & $\begin{array}{l}\text { Average } \\
\text { value }\end{array}$ & $\begin{array}{l}\text { Valuable } \\
\text { very } \\
\text { valuable }\end{array}$ & $\begin{array}{l}\text { Val } \\
\text { valu }\end{array}$ \\
\hline 8.33 & 16.67 & 37.5 & 37.5
\end{tabular}
journal articles and other professional development materials $(\mathrm{N}=47)$

3. Feeling connected to a wider

$\begin{array}{llll}10.42 & 8.33 & 41.67 & 38.58\end{array}$
professional community of practice $(\mathrm{N}=48)$

4. Feeling empowered, able to take a $\begin{array}{lllll}4.26 & 25.53 & 23.40 & 29.79 & 17.02\end{array}$ stand, and question and challenge the views of government $(\mathrm{N}=47)$

5. Being able to access colleagues I can

$\begin{array}{lllll}2.08 & 10.42 & 33.33 & 31.25 & 22.92\end{array}$
ask for advice and information on professional issues $(\mathrm{N}=48)$

6. Being able to participate in $\begin{array}{lllll}4.17 & 16.67 & 18.75 & 31.25 & 29.17\end{array}$ discussions and debates about policy and political issues relating to social work practice $(\mathrm{N}=48)$

7. Being able to post and share information on issues relevant to the social work community $(\mathrm{N}=48)$

8. Opportunity to show my support for issues and causes in which I believe $(\mathrm{N}=48)$ 
TABLE 3 Frequency of participant's activity in SWAN (percentages)

\begin{tabular}{|c|c|c|c|c|c|}
\hline Actions & Never & Rarely & Sometimes & Often & $\begin{array}{l}\text { Most of } \\
\text { the time }\end{array}$ \\
\hline $\begin{array}{l}\text { How often do you start new posts in the SWANZ } \\
\text { group? }(\mathrm{N}=48)\end{array}$ & 39.58 & 31.25 & 22.92 & 6.25 & \\
\hline $\begin{array}{l}\text { How often do you add comments to posts in the } \\
\text { SWANZ group? }(\mathrm{N}=47)\end{array}$ & 14.89 & 27.66 & 51.06 & 6.38 & \\
\hline $\begin{array}{l}\text { How often do you 'like' new posts or comments in } \\
\text { the SWANZ group? }(\mathrm{N}=48)\end{array}$ & 4.17 & 8.33 & 50 & 33.33 & 4.17 \\
\hline $\begin{array}{l}\text { How often do you share SWANZ group posts } \\
\text { with friends or other Facebook groups? }(\mathrm{N}=48)\end{array}$ & 16.67 & 29.17 & 41.67 & 10.42 & 2.08 \\
\hline
\end{tabular}

TABLE 4 Reasons for reluctance to express policy or political views

\begin{tabular}{lll}
\hline Reasons & $\begin{array}{l}\text { Percentage } \\
\text { agreeing }\end{array}$ & N \\
\hline $\begin{array}{l}\text { I worry that I may be subject to critical comments by others in the } \\
\text { group who do not share my views. }\end{array}$ & 70.59 & 34 \\
I'm not always sure what I really think and I'm concerned I may & 41.18 & 30 \\
not express myself clearly. & 33.33 \\
$\begin{array}{l}\text { I prefer to keep my view on policies and politics to myself. } \\
\text { I'm concerned that current or future employers may be able to } \\
\text { monitor my political views and this may affect my career }\end{array}$ & 31.25 & 31 \\
$\begin{array}{l}\text { prospects. } \\
\text { My employment contract prohibits me from expressing views on } \\
\text { policy or politics in public forums }\end{array}$ & 19.35 & 31 \\
$\begin{array}{l}\text { I don't think it is appropriate for social workers to share their } \\
\text { political or policy views in a social media platform. }\end{array}$ & 16.13 &
\end{tabular}

